\title{
HYDROPONIC DEVICES FOR GREEN FODDER PRODUCTION: A REVIEW
}

Andrius GRIGAS, Institute of Agricultural Engineering and Safety, Faculty of Agricultural Engineering, Vytautas Magnus University, Studentų 15A, Akademija, Kaunas distr., Lithuania; agrigas1@ gmail.com

Aurelija KEMZŪRAITE், Institute of Agricultural Engineering and Safety, Faculty of Agricultural Engineering, Vytautas Magnus University, Studentu 15A, Akademija, Kaunas distr., Lithuania; aurelija.kemzuraite@ vdu.lt (corresponding author)

Dainius STEPONAVIČIUS, Institute of Agricultural Engineering and Safety, Faculty of Agricultural Engineering, Vytautas Magnus University, Studentų 15A, Akademija, Kaunas distr., Lithuania; dainius.steponavicius@ vdu.lt

In traditional farming, plants require a lot of space (growing area), they consume a large amount of water, absorb a small percentage of nutrients in soil and are completely dependent on meteorological conditions. Therefore, growing crops in this way entails high costs and a high risk of invested funds. One of the measures to reduce these factors is the use of hydroponics.

In the study six types of hydroponic systems (HS) plant constructions based on plant nutrient supply technology were reviewed: ebb and flow HS; nutrient film technique (NFT) HS; aeroponics; deep water culture HS; "wick" HS and drip-irrigation HS. In addition, a review of the structural design of the hydroponic systems identified their advantages and disadvantages in green fodder production.

The most promising technology for the cultivation of green fodder is the NFT HS. This cultivation technology is appreciated in feed production for its highly utilized growing room volume and closed-loop irrigation solution to plants, which allows it to be easily automated based on solution parameters. Seven farms already have this technology in place in Lithuania. In order to optimize hydroponic fodder cultivation technology, it is expedient to improve NFT equipment and process control systems.

Keywords: green fodder, hydroponic nutrient, hydroponic systems, nutrient film technique.

\section{INTRODUCTION}

Efficiency is the primary goal of every business. The agricultural sector, which aims to produce the highest and highest quality yields at the lowest possible cost, is no exception. As the world population grows rapidly, the need for food and feed for livestock will eventually increase. However, the world is full in unproductive soils, and often, climate change also results in adverse meteorological conditions for agricultural production. Therefore, traditional farming (growing in the soil) makes it increasingly difficult to produce maximum and high-quality crops. In order to reduce cultivation costs and to grow crops in unproductive areas, soil-less cultivation systems are being used more often (Sardare, Admane, 2013). In traditional farming systems, plants require a lot of space (growing area), consume a large amount of water, absorb a small percentage of nutrients and are completely dependent on meteorological conditions. Therefore, growing crops in this way entails high costs and a high risk of invested funds. One of the measures to reduce these factors is the use of hydroponics. Hydroponics is a method of growing plants without using soil. Instead, this method uses a mineral nutrient solution that allows nutrient uptake more efficiently than using soil (Jensen, 1997).

As early as the 19th century, two scientists, J. von Sachs and W. Knop, demonstrated that terrestrial plants can grow in nutrient solution, i.e., without soil. They said plants can meet all their needs only from inorganic elements and sunlight. Cultivating plants by irrigating their roots with nutrient solution is called hydroponics or hydroponic cultivation (Stanhill, Enoch, 1999). Hydroponic farming is not a new farming method but a technology that has been used for thousands of years. The floating and hanging gardens of Babylon in China are the oldest known examples of hydroponic cultivation, but later such cultivation technology was not widely used. It is only relatively recently that there is a renewed interest in hydroponic farming, especially in areas and regions where soil and weather conditions are unsuitable for conventional farming, such as deserts. In 1924, the term Hydroponics was proposed by W. F. Gericke - a professor from the University of California, known as the father of hydroponics. Until 1924 the cultivation of plants without soil has been called variously: Aquaculture, Chemiculture or Nutriculture. W. F. Gericke used hydroponics technology to grow fruits, vegetables, flowers, ornamental plants, and root crops (Savvas, 2003).

During World War II, British and American armies used this cultivation method to grow food for soldiers stationed in deserts and remote areas where traditional soil-growing techniques were not possible (Stanley, 1998). Subsequently, hydroponic plant production spread widely around the world, and since the 1960s. it has become an important 
industry, especially in the US, Russia, France, Germany, Holland, Australia, the Middle East and South Africa. The main reason for this is that hydroponically grown crops require much less cultivated area than traditional agriculture. A study by the Australian Government found that there are about 40.700 hectares of high-intensity hydroponic farming worldwide, with annual sales of 6-8 billion dollars (Wittwer, Castilla, 1995). The US Navy also uses hydroponics to grow vegetables on submarines, and NASA to provide food for astronauts traveling on long space flights (Pebrero, 2009).

Thus, hydroponics allows people to grow food and forage in areas where conventional agriculture is simply not possible, such as in areas with very dry climates (Okemwa, 2015). This farming method allows people in these areas to feed on the local produce grown and to expand their food production. Also, hydroponics is useful in densely populated urban areas where there is no or very expensive cultivated land (Schnitzler, 2012). Finally, hydroponics can be useful in areas with insufficient sunlight or warm climates (Jensen, Malter, 1995).

Hydroponics systems for crop production are currently undergoing rapid development and improvement. They are becoming increasingly superior to conventional plant cultivation because they make it easier to adjust smart technology. Hydroponic greenhouses are used in areas where plant seasons are shorter. They can control light and temperature for higher yields. The use of computer control of a hydroponic operation has revolutionized decision-making procedures (Jones, 2005). Therefore, hydroponics can be fully automated, requiring minimal maintenance of such a system. This would reduce production costs, save time and produce better quality. For example, solutions used in hydroponic devices are usually evaluated based on their electrical conductivity and pH. However, electrical conductivity and $\mathrm{pH}$ can not provide sufficient information about concentrations of individual ions $\left(\mathrm{NO}_{3}\right.$, $\mathrm{K}$, and $\mathrm{Ca}_{2}$ ). Cho et al. (2018) developed of an on-site ion monitoring system based on ion-selective electrodes that can automatically calibrate sensors and measure the concentrations of ions in hydroponic solutions (Cho et al., 2018). The use of hydroponic plant growing technology also has various advantages for physiological, biochemical, or molecular studies that allow easy monitoring and measurement of root growth and morphology throughout their life cycle (Arteca, Arteca, 2000).

Hydroponics fodder production is said to be an effective alternative technology for sustainable livestock production (Ramteke et al., 2019). Hydroponic reduce the use of water in fodder production. For example, to produce one kg of fresh hydroponic fodder, about 3.0 liters of water is required (Ramteke et al., 2019). Hydroponically germinated grain fodder chemical composition, organic matter digestibility and metabolizable energy levels are changed with barley harvest days. It is reported that the 7th day is the best harvest day, in terms of barley fodder production (Akbağ et al., 2014). The fact that hydroponics has been used for food production since ancient times has led to the relatively recent development of hydroponics for feed production and the potential of hydroponics equipment for feed has not yet been sufficiently revealed.

The aim of this study was to review the features of hydroponics constructions and to evaluate their potential in green fodder production.

\section{MATERIALS AND METHODS}

In the study using the method of scientific literature analysis, six types of hydroponic systems (HS) constructions were reviewed based on plant nutrient supply technology: ebb and flow HS; nutrient film technique (NFT); aeroponics; deep water culture HS; "wick" HS and drip-irrigation HS. In addition, a review of the structural design of the hydroponic systems identified their advantages and disadvantages in feed production.

\section{RESULTS AND DISCUSSION}

Hydroponic devices. Hydroponic systems can be divided into six types according to plant feeding technology (Ernst, Busby, 2009). All of these systems have some common components (pump, frame, piping, etc.), regardless of the method used to feed the plants. Cultivation media can be any that can support plant growth and development, such as various fibers, minerals, solutions, and composites, but the soil is not considered a hydroponic culture medium.

Ebb and flow system. It's used to grow plants hydroponically. It works by periodically flooding the plant roots with a nutrient solution (Nicola et al., 2006). The main part of this system is the growing tray 4 where the plants are grown (Figure 1). The programmable timer activates the irrigation pump 1 and the water (or nutrient solution) is fed to the growing tray 4 . The nutrient solution fills the system until it reaches the height of the preset overflow valve 8 . In addition, a mechanical filter can be used to prevent small plant roots from getting into it. It is advisable that the overflow valve should be set approximately $2 \mathrm{~cm}$ below the top of the roots of the plant. This type of irrigation and nourishment in particular reduces the likelihood of the emergence of various pathogens in the plant's root zone.

This concept of plant irrigation and nourishment has been used for many years. Mostly this cultivation method is used for growing potted plants, which are placed in trays and flooded for up to 10 minutes until the nutrient solution reaches a certain level (Bartok, 1989). This technology has been rarely used in forage production because it has been shown to be ineffective when compared to other hydroponic technologies. During growth, the root clogs the overflow valve, resulting in a significant increase in production costs. 
8

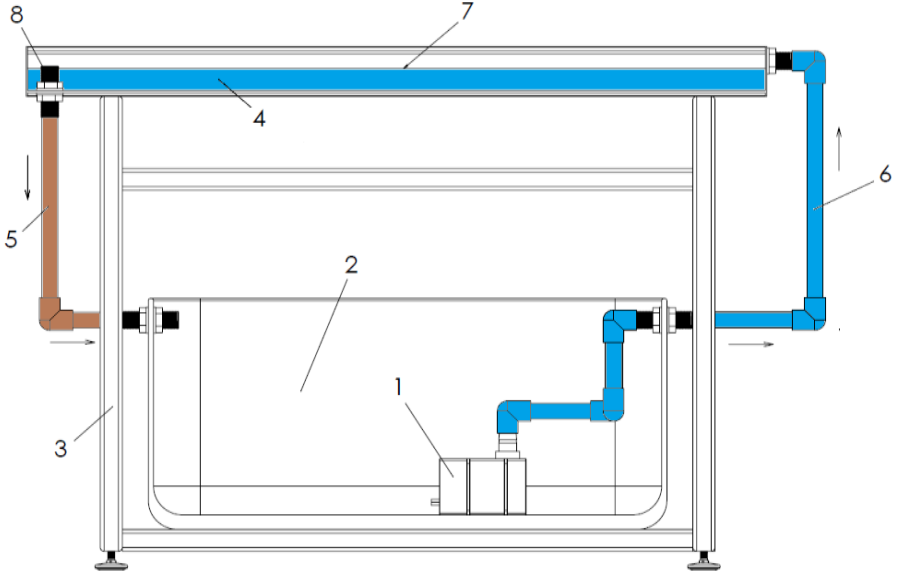

Figure 1. Technological scheme of ebb and flow system:

1 - pump, 2 - nutrient solution tank, 3 - frame, 4 - growing tray, 5 - return solution tube, 6 - solution supply tube, 7 - solution level in the cultivation shelf, 8 - transfer valve

\section{Advantages:}

- Nutrient solution can be reused;

- Reduce the likelihood of the presence of pathogens in feed;

- Evenly germinating all spread seeds;

- Low production costs.

\section{Disadvantages:}

- Salt and mineral deposits can easily form in the culture medium;

- Germinated seeds clog the overflow valve;

- Growing trays cannot be removed for more convenient washing.

Nutrient film technique (NFT). The main feature of the Nutrient Film Technique is the irrigation and nutrient solutions are recycled several times (Burrage, 1992). This system is widely adapted to the growing of various plants and is an ideal solution for growing short-cycle plants such as cereals, lettuce, etc. Larger NFT systems may also be applicable to longer growing plants such as cucumbers and tomatoes (Sheikh, 2006).

The NFT system can be designed in a variety of ways, but the most commonly used technology is when the nutrient solution is fed through a pipeline 6 to a tilted growing tray 4 (Figure 2). Water or nutrient solution forms a thin film (2-3 mm thick) in which the plant roots absorb nutrients. This technology is similar to the ebb and flow HS for several reasons: it incorporates a recirculation pipeline that allows the used water or nutrient solution to be diverted from the nutrient solution reservoir to a container that can be cleaned. Also, these growing systems are completely dependent on watering pumps to provide solution recirculation and plant nourishment.

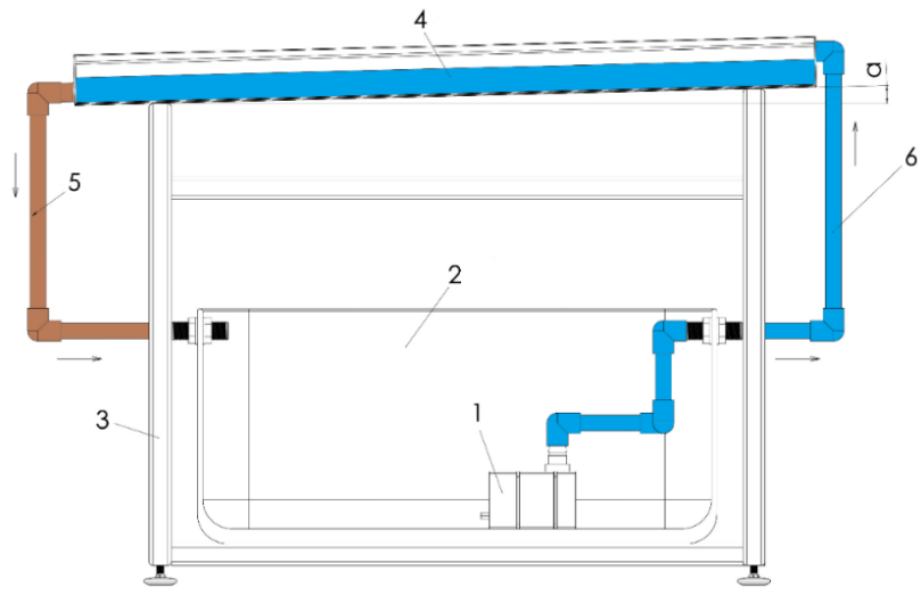

Figure 2. Technological scheme of the Nutrient Film Technique system:

1 - pump, 2 - nutrient solution tank, 3 - frame, 4 - growing tray,

5 - solution return tube, 6 - solution supply tube, $\alpha$ - shelf angle

\section{Advantages:}

- Constant movement of the solution in the irrigation system prevents it from stopping;

- The only hydroponic system that is effective in forage growing;

- No parts that could clog;

- Low cost of nutrient solution.

\section{Disadvantages:}

- Due to the tilt angle of the growing tray, the germinated seeds flow downwards during irrigation;

- With the low irrigation flow rate, the top layer of germinated seeds may not be adequately wetted.

Structurally, this system has 2 main components: a growing tray and a reservoir of nutrient solution that holds water with the macro- and micro-nutrients dissolved therein. The basic principle of this system is simple: the rack must be placed at an angle so that the water flows down to the lowest point of the rack. Flowing water or nutrient solution forms a thin film of solution with excess flowing from the shelf to the collection gutter. It returns the solution to a nutrient solution tank for reuse or another container for further processing (Guo, 2017).

The ebb and flow system can be used for seed germination and green fodder production. This hydroponic cultivation technology is most widely used in feed production. Seven farms already have this technology in place in Lithuania.

In the past, this technology was prevalent in lettuce growing, but by modifying the growing trays for growing, it can sprout various grains and produce fresh, nutrient-rich green fodder. These trays are usually much wider than the trays used in lettuce growing, so that more seeds can be sprouted at one time. In feed production, NFT system reduces humidity in growing room and water consumption compared to other hydroponic systems. The lower ambient humidity allows this system to be used in slightly warmer conditions, promoting growth intensity but not the growth of mold and various pathogens (Salinger, 2018). 
It is worth noting that this technology is currently the only option for efficient industrial growth of hydroponic feed. Usually, this cultivation technology is valued in feed production because of the excellent utilization volume of the growing room. This system is easy to construct using more than one vertical growing level. Experimental research carried out in Lithuania using NFT hydroponic system confirmed the hypothesis that the tilting angle of the rack for cultivation has a significant effect on the yield of wheatgrass grown hydroponically for 7 days. Analyzing the results it was found that the highest $(5428.0 \pm 279.0 \mathrm{~g})$ yield of grasses after 7 days of cultivation was shelved at $6.5 \%$. In addition, in the course of the studies it was noticed that in all investigated cases wheatgrass at the rear of the shelves was significantly lower in height (Figure 3). This trend was particularly noticeable when the racking angle of the racks did not exceed $5 \%$. It is likely that the root cause of this problem is the accumulation of the solution used for plant nutrition at the ends of the shelves. This resulted in excessive soaking of the roots of the plants, which hindered the growth process. Therefore, in future studies it would be appropriate to optimize the surface shape of the shelves (Grigas et al., 2019).

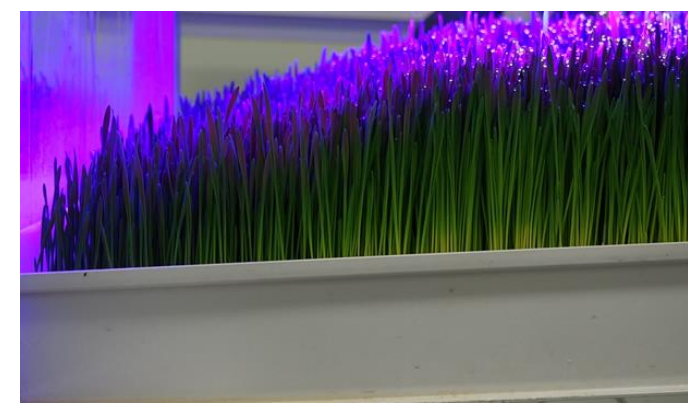

a)

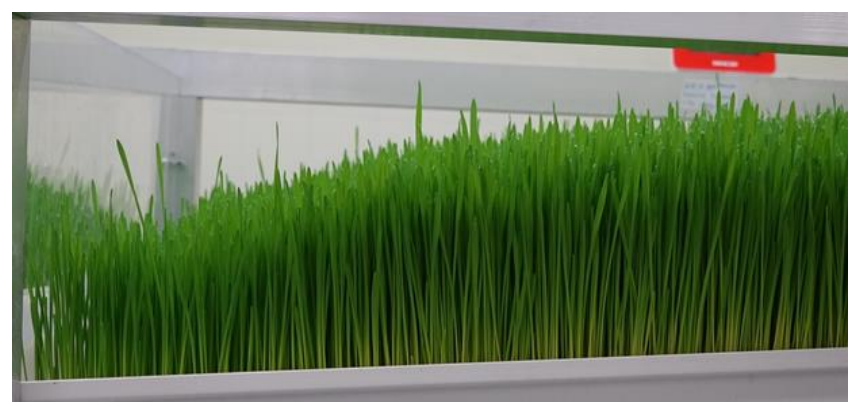

b)

Figure 3. Appearance of wheatgrass at the rear of the growing trays using LED (a) and fluorescent lamps (b) for growing lighting

Aeroponics. Growing plants by humidifying the air in the root area of the plant is called aeroponics or growing plants by spraying the roots with an aerosol of nutrient solution. This concept and idea of growing plants in the air by feeding them from the environment is not very old. For scientists, the idea came from observing plants growing on rocks near a waterfall. They observed that the plants had successfully grown in rocks near waterfalls, although their roots were hanging in the open air (Lakhiar et al., 2018).

Instead of immersing the roots in water as in the ebb and flow system (Figure 1), the roots are moistened at intervals by spraying the nutrient solution with high pressure nozzles (Figure 4). This type of irrigation and nourishment provides high levels of dissolved oxygen and nutrients to plant roots. Unused water and nutrients are easily returned to the nutrient solution tank, from which the nutrient solution is used for re-irrigation (Lakhiar et al., 2018).

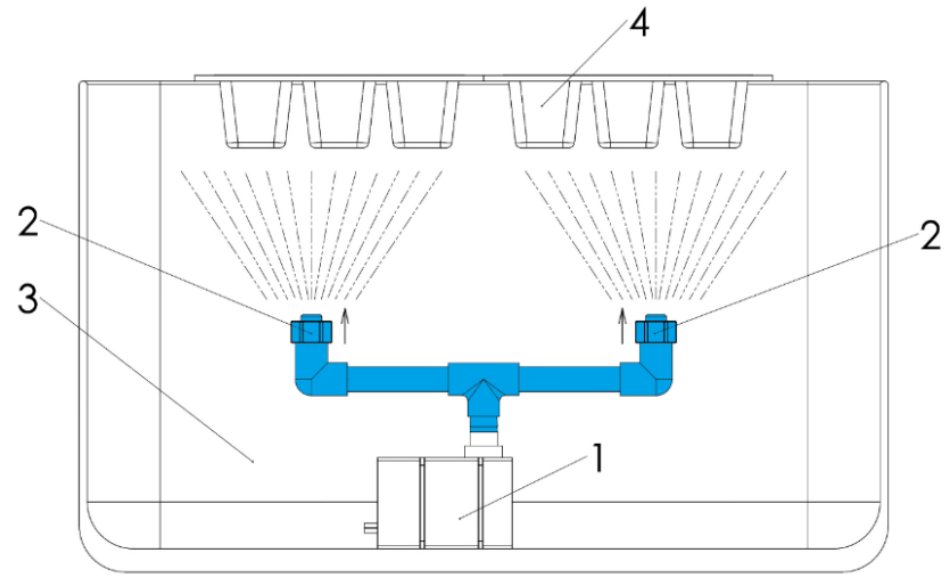

Figure 4. Aeroponics technological plan:

\section{Advantages:}

- High oxygen content for plant roots;

- Faster plant growth;

- Reuses the nutrient solution.

\section{Disadvantages:}

- High pH fluctuations.

- The system is completely structurally unsuitable for forage production;

- Common root diseases;

- Nozzles often clog;

- The root should be watered frequently, which means that there is a risk of root drying out.

1 - pump, 2 - jets, 3 - nutrient solution tank, 4 - plant growing jars

A major disadvantage of this system is the dependence on the irrigation system. The roots of the plants must be constantly moist. As the moisture evaporates, the roots quickly shrink, dry and die. To prevent this, in the event of failure of the pump or spray system, a back-up mechanism that can continue spraying (irrigation) processes is essential (Birkby, 2016). The main advantage of this cultivation system is the yield and the high oxygen content of the plants in the watering / spraying process. Scientists have proven that crops grown using this technology produce yields that can be several times higher than those of other alternative soil-less systems. This is an enormous advantage, and the main reason for this is that aerosol spraying technology for root cultivation gives plants roots much more oxygen than other systems (Lakkireddy et al., 2018).

Despite the valuable advantages of this system, growing large quantities of feed would be quite difficult. Moreover, this growing technology in vertical agriculture significantly increases the relative humidity of the room, which increases the likelihood of the presence of various pathogens in the feed. 
Deep water culture hydroponic system. Deep Water Culture (DWC) is a hydroponic growing method for growing plants by keeping their roots continuously in an oxygenated solution full of nutrients and water (Figure 5). This system differs from other hydroponic cultivation methods in which plants are watered and only on a given feeding schedule (Sardare, Admane 2013). The main part of this system is the reservoir 1 where the plants are grown. This component should be filled with water or nutrient solution. A very important part of this system is the monitoring and control of the water level (Saaid, 2013). In comparison, in aeroponics (Figure 4), plant roots are hanged, kept in the air, and watered or sprayed constantly. With this technology, the roots of cultivated plants are drowned in water, which is continuously oxygenated 24 hours a day (Butcher et al., 2017).

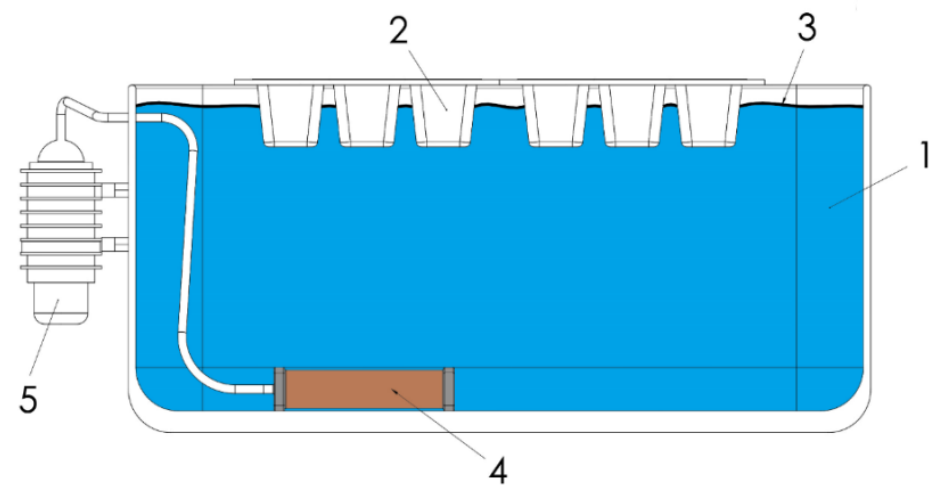

Figure 5. Deep Water Culture technological plan: 1 - Nutrient solution tank, 2 - Plant growth jars, 3 - Nutrient solution level, 4 - Air diffuser, 5 - Air pump
Advantages:

- Ideal for soaking-loving, short growth cycle plants;

- Allows the plant to grow a large root mass;

- Relatively fewer plants are grown but their yield is higher;

- Low system installation costs.

\section{Disadvantages:}

- Required growing medium;

- With this system, plants are prone to root diseases;

- Root mass can grow so large that clog irrigation cavities;

- The system is completely inadequate for efficient feed production.

In the industry, DWC system is appreciated for its ease of service and the ability to regulate the oxygen content of plant roots. It is worth noting that the use of such a growing system significantly reduces the amount of feed fertilizer. It also reduces maintenance costs and monitoring time. However, this system is not recommended for hydroponic feed production.

Wick system. In the Wick system, the root of the plant is fed by a strip of porous material that is immersed into a liquid that is capillally fed to a tray, jar or other absorbent medium (Figure 6). Typically, for efficiency purposes, such systems employ multiple irrigation strips to ensure sufficient water or nutrient supply to plants. The system itself is usually installed at a minimum distance above the feed solution tank. In this case, the solution does not need to be delivered very far to reach the plant (Semananda et al., 2018).

3

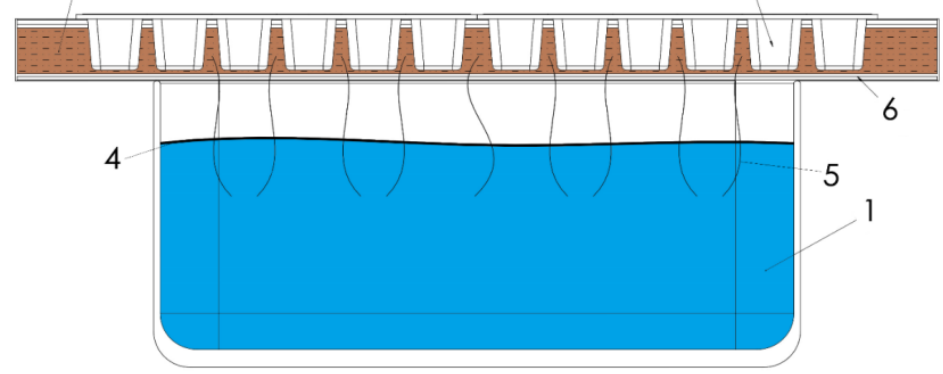

Figure 6. Wick system technological plan:

1 - nutrient solution tank, 2 - plant growth jars, 3 - solution absorbing medium, 4 - nutrient solution level, 5 - porous material strip, 6 - growing tray

\section{Advantages:}

- The system requires little maintenance.

\section{Disadvantages:}

- The system is not suitable for plants that require a lot of nutrient solution;

- High system installation costs;

- Difficult to apply to vertical cultivation;

- The system is not suitable for forage production due to less efficient seed feeding.

The irrigation strip ("wick") is the most important part of this system because without good water absorption, plants will not be able to get the right amount of moisture and nutrients. When manufacturing such systems, it is usually advisable to test several materials to determine which material strips are most effective to use. When choosing a material, it must be taken into account that it must absorb a large amount of water, but at the same time be protected from rotting (Mathes, 2016). The most commonly used materials in such systems are fiber ropes, propylene felt strips, various candle wicks, rayon ropes, plaited polyurethane yarns, wool felt, wool ropes or ribbons, nylon cords, fabrics of old clothing or blankets and so on. (Semananda et al., 2018).

Selecting a tank for such a system is the easiest task. The efficiency of the system is not directly dependent on the nutrient solution reservoir, but it is important to keep in mind that the water level in the reservoir is always high enough for the nutrient solution to reach the growth medium and root area. It is also important to periodically replenish the tank with nutrients or completely replace the nutrient solution with a new one. This is usually done in order to prevent algae 
and / or microorganisms from growing on the water, especially if the tank is not exposed to direct sunlight. This system is not suitable for forage production due to less efficient seed feeding.

Drip hydroponic system. Drip technology is an active hydroponic system. It uses a pump to regularly feed the plants with nutrients and water (Figure 7). This system is also referred to in the literature as the "trickle" or micro irrigation system. As the name implies, the system uses small hoses to deliver water or nutrient solution directly to the plant root area (Palm et al., 2018).

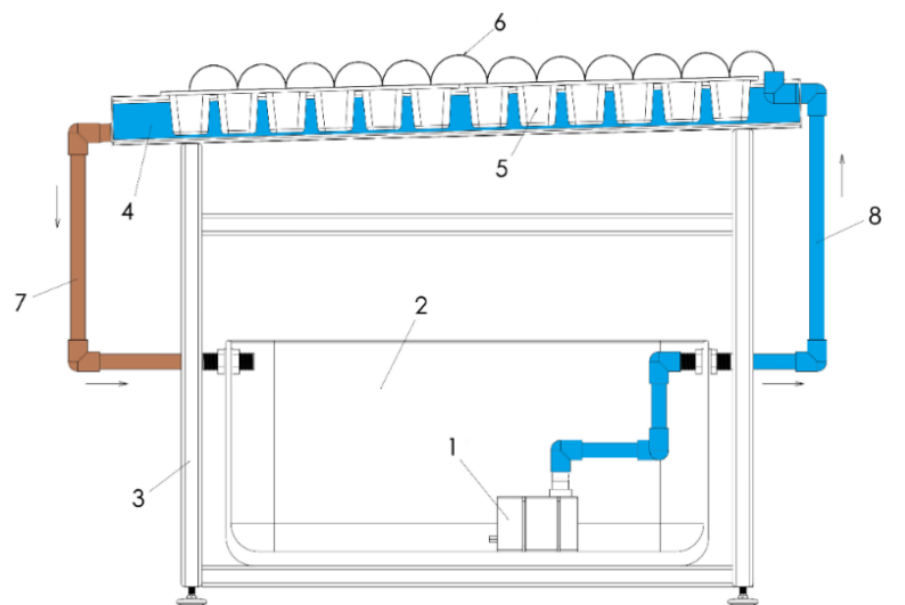

Advantages:
- Any type of growing medium can be used;
- Increased absorption of nutrient solution.

Figure 7. Technological plan of drip system:

1 - pump, 2 - nutrient solution tank, 3 - frame, 4 - growing tank,

5 - plant growth jars, 6 - watering hose, 7 - return solution tube, 8 - solution supply tube

\section{Disadvantages:}

- The system can easily become clogged;

- Inefficient system for forage production;

- Frequent maintenance and service required.

Instead of aeroponics or Nutrient Flow Technique, the nutrient solution is slowly added to the plant roots area (Sharma, 2018). The main advantage of this technology is that the system uses less water. Such cultivation technology is also widely used in outdoor gardens to supply water and nutrients to individual plants. The advantage of this system is that it also performs well in both soil and growing media in hydroponics. In fact, such a system was originally designed to grow field crops in Israel. Its purpose was to improve the water efficiency of arable crops. Subsequently, the aforementioned drip method has been successfully applied to hydroponics.

\section{CONCLUSIONS}

Nowadays, seed germination and hydroponic grass production are increasingly used not only for healthy nutrition but also for animal feed. Seed germination is carried out in hydroponic systems rather than in soil. Hydroponically grown sprouts of various seeds can be effectively used on small farms producing high quality and value products, where conventional feed costs are high and when changes in feed quality (e.g., less starch, more lysine, vitamins, etc.) result in germination benefits. It is stated that sprouted seeds with higher enzyme content have very good prospects of being used in future food and feed production. The main factors influencing the yield and quality of meadow seeds are the soaking of the germinated seeds, their disinfection, lighting and the electrical conductivity of the nutrient solution. The most promising technology for the cultivation of fodder is the irrigation of the roots of the plants with a irrigation solution (Nutrient Film Technique). Scientists say it is still necessary to optimize the germination process of various seeds, taking into account germination conditions and equipment.

\section{REFERENCES}

1. Akbağ H. I., Türkmen O. S., Baytekin H., Yurtman İ. Y. 2014. Effects of Harvesting Time on Nutritional Value of Hydroponic Barley Production. Turkish Journal of Agricultural and Natural Sciences, Spec. Iss. 2, pp. 1761-1765.

2. Arteca R. N., Arteca J. M. 2000. A Novel Method for Growing Arabidopsis Thaliana Plants Hydroponically. Physiologia Plantarum, Vol. 108, Iss. 2, pp. 188-193. https://doi.org/10.1034/j.1399-3054.2000.108002188x./

3. Bartok J. W. Jr. 1989. Ebb and Flow from an Engineer's Viewpoint. Ornamentals Northwest Archives, Vol. 13, pp. 13-14.

4. Birkby J. 2016. Vertical Farming. ATTRA Sustainable Agriculture NCAT IP516, pp. 1-12.

5. Burrage S. W. 1992. Nutrient Film Technique in Protected Cultivation. Symposium on Soil and Soilless Media under Protected Culti vation in Mild Winter Climates, ISHS Acta Horticulturae 323, 23-38. ttps://doi.org/10.17660/ActaHortic.1993.323.1

6. Butcher J. D., Laubscher C. P., Coetzee J. C. 2017. A Study of Oxygenation Techniques and the Chlorophyll Responses of Pelargonium tomentosum Grown in Deep Water Culture Hydroponics. HortScience, Vol. 52, Iss. 7, pp. 952-957. https://doi.org/10.21273/HORTSCI11707-16

7. Cho,W. J., Kim H. J., Jung D. H., Kim D. W., Ahn T. I., Son J. E. 2018. On-site Ion Monitoring System for Precision Hydroponic Nutrient Management. Computers and Electronics in Agriculture, Vol. 146, pp. 51-58. https://doi.org/10.1016/j.compag.2018.01.019

8. Ernst, J. V., Busby, J. R. 2009. Hydroponics: Content and Rationale: Technology is Diverse Enough in Nature that It Can Be Addressed by a Variety of Content Areas, Serving as a True Integrator. The Technology Teacher, Vol. 68,Iss. 6, pp. 20-25. https://doi.org/10.21061/jte.v20i2.a.2

9. Grigas A., Steponavičius D., Steponavičienė A. 2019. Technological Factors Affecting Wheat Seeds Fodder Production Sprouting Hydroponically. Agroinžinerija ir Energetika, No. 24, pp. 138-147. (In Lithuanian) 
10. Guo Y. 2017. Development of a Design System for the Sprout Tide-type Irrigation Device. Proceedings of the 2nd International Conference on Materials Science, Machinery and Energy Engineering, Vol. No. 123, pp. 1797-1802. https://doi.org/10.2991/msmee-17.2017.328

11. Jensen M. H. 1997. Hydroponics. HortScience, Vol. 32, Iss. 6, pp. 1018-1021. https://doi.org/10.21273/HORTSCI.32.6.1018

12. Jensen M. H., Malter A. J. 1995. Protected Agriculture: A Global Review, World Bank Publications (Vol. 253).

13. Jones J. B. 2005. Hydroponics: a Practical Guide for the Soilless Grower, CRC Press. https://doi.org/10.1201/9781420037708

14. Lakhiar I. A., Gao J., Syed T. N., Chandio F. A., Buttar N. A. 2018. Modern Plant Cultivation Technologies in Agriculture under Controlled Environment: A Review on Aeroponics. Journal of Plant Interactions, Vol. 13, Iss. 1, pp. 338-352. https://doi.org/10.1080/17429145.2018.1472308

15. Lakkireddy K. K. R., Kasturi K., KRS S. R. 2018. Role of Hydroponics and Aeroponics in Soilless Culture in Commercial Food Production. Research \& Reviews: Journal of Agricultural Science and Technology, Vol. 1(3), pp. 1-8.

16. Mathes R. 2016. Wick System. Available at http://www.hydrogarden.in/2016/02/18/wick-system/ (accessed on 27/03/2019).

17. Nicola S., Hoeberechts J., Fontana E. 2006. Ebb-and-Flow and Floating Systems to Grow Leafy Vegetables: A Review for Rocket, Corn Salad, Garden Cress and Purslane. The $8^{\text {th }}$ International Symposium on Protected Cultivation in Mild Winter Climates "Advances in Soil and Soilless Cultivation under Protected Environment“, ISHS Acta Horticulturae, Vol. 747, pp. 585-593. https://doi.org/10.17660/ActaHortic.2007.747.76

18. Okemwa E. 2015. Effectiveness of Aquaponic and Hydroponic Gardening to Traditional Gardening. International Journal of Scientific Research and Innovative Technology 2(12), 21-52.

19. Palm H. W., Knaus U., Appelbaum S., Goddek S., Strauch S. M., Vermeulen T., Kotzen, B. 2018. Towards Commercial Aquaponics: A Review of Systems, Designs, Scales and Nomenclature. Aquaculture International, Vol. 26(3), pp. 813-842. https://doi.org/10.1007/s10499-018-0249-z

20. Pebrero L. 2009. Research and statistics. Available at http://myresearch08-09.blogspot.qa/2009/02/review-of-related-literature.html (accessed on 27/03/2019).

21. Ramteke R., Doneria R., Gendley M. K. 2019. Hydroponic Techniques for Fodder Production. Acta Scientific Nutritional Health, Vol. 3(5), pp. $127-132$.

22. Saaid, M. F., Yahya, N. A. M., Noor, M. Z. H., Ali, M. M. 2013. A Development of an Automatic Microcontroller System for Deep Water Culture (DWC). Proceedings of the IEEE 9th International Colloquium on Signal Processing and its Applications IEEE, pp. 328-332, Kuala Lumpur, Malaysia. https://doi.org/10.1109/CSPA.2013.6530066

23. Salinger M. 2018. Producing hydroponic fodder. Available at https://www.powerhousehydroponics.com/producing-hydroponic-fodder/ (accessed on 27/03/2019).

24. Sardare M. D., Admane S. V. 2013. A Review on Plant without Soil-Hydroponics. International Journal of Research in Engineering and Technology, Vol. 2, Iss. 3, pp. 299-304. https://doi.org/10.15623/ijret.2013.0203013

25. Savvas D. 2003. Hydroponics: A Modern Technology Supporting the Application of Integrated Crop Management in Greenhouse. Journal of Food Agriculture and Environment, Vol. 1, pp. 80-86.

26. Schnitzler W. H. 2012. Urban Hydroponics for Green and Clean Cities and for Food Security. International Symposium on Soilless Cultivation, ISHS Acta Horticulturae, Vol. 1004, pp. 13-26. https://doi.org/10.17660/ActaHortic.2013.1004.1

27. Semananda N., Ward J. Myers B. 2018. A Semi-Systematic Review of Capillary Irrigation: The Benefits, Limitations, and Opportunities. Horticulturae 4(3), 23. https://doi.org/10.3390/horticulturae4030023

28. Sharma N., Acharya S., Kumar K., Singh N., Chaurasia O. P. 2018. Hydroponics as an Advanced Technique for Vegetable Production: An Overview. Journal of Soil and Water Conservation, Vol. 17(4), pp. 364-371. https://doi.org/10.5958/2455-7145.2018.00056.5

29. Sheikh B. A. 2006. Hydroponics: Key to Sustain Agriculture in Water Stressed and Urban Environment. Pakistan Journal of Agriculture, Agricultural Engineering and Veterinary Sciences, Vol. 22, pp. 53-57.

30. Stanhill G., Enoch Z. H. 1999. Ecosystems of the World. 20, Greenhouse Ecosystems, Chemosphere, Amsterdam.

31. Stanley D. 1998. Hydroponic strawberries avoid soil pests. Agricultural Research, Vol. 46(11), pp. 1-10.

32. Wittwer S. H., Castilla N. 1995. Protected Cultivation of Horticultural Crops Worldwide. HortTechnology, Vol. 5, Iss. 1, pp. 6-23. https://doi.org/10.21273/HORTTECH.5.1.6 